\title{
Ending life with grace and agreement
}

M aking the decision to withdraw or withhold lifesustaining care is difficult at the best of times, but when families and caregivers disagree about the course of action, the conflict disrupts patient care and consumes enormous personal resources for all parties.

The case of Samuel Golubchuk, an elderly and very ill man at the threshold of multiple organ failure in a Winnipeg intensive care unit, illustrates this problem. The doctors wanted to withdraw care, and they met with the family on several occasions to seek consent; however, a religious impasse was reached, and Mr. Golubchuk's son and daughter would not give consent.

"Doctors don't know everything," Percy Golubchuk told CTV News, "God is the major doctor."1

Remarkably, God is a serviceable lawyer, too. The family precipitously went to court and, "without notice to the defendants," got an injunction forbidding the hospital and doctors "from removing the plaintiff ... from life support care, ventilation, tube feeding, and medication" - an order that if violated could lead to fines or imprisonment. ${ }^{2}$ The family believes that their father "should be kept alive as long as his heart is beating and he's functioning and has got brain activity," according to their lawyer and that "Any hastening of the death process is murder." ${ }^{3}$

If this is murder, many of Canada's doctors belong in jail. Legally, doctors are practitioners of a duty of care. An obligation to provide extraordinary care to dying patients, including patients who are minimally responsive, forces one to breach the everyday duty of care, which is to provide the best balance between probable harms and foreseeable benefits. That is why an approach that excludes the option to withhold or withdraw life-sustaining care is unworkable.

Mr. Golubchuk's case is in no way unique. In England, the case of Airedale NHS Trust v. Bland also dealt with a patient in a persistent vegetative state. ${ }^{4}$ But instead of a family that refused to consent, the family accepted that their loved one should die, and it was hospital administrators who feared that disconnecting the feeding tube would be illegal and murder - the opposite of Golubchuk's case. England's highest court decided that removing the feeding tube was an "omission" rather than an "act" that triggers murder and permitted it to be removed. Tony Bland died shortly thereafter.

What can we learn from the Golubchuk and Bland cases? First, the considered withholding or withdrawal of life sustaining care is not "murder." Lawyers may make it seem so by exploiting the dubious distinction between acts and omissions - when in truth discontinuing invasive procedures such as tube feeding is both an omission (e.g., discontinuation of care) and an act (e.g., removal of a tube). Wise judges would reject this linguistic charade and bravely adopt an ethical approach to decision-making, which al- ways emphasizes the best interest of the patient. In these circumstances, it is the disease that kills the patient, not the doctor or the treatment.

Second, some families will overreach in their demands to preserve life, often because they use fundamentalist religious beliefs or cultural norms to narrowly define the best interest of the patient. In dying, just as in living, no right, including the constitutional freedom to one's religion, is absolute. Requiring caregivers to stand in the way of the natural process of dying by forcing them to impose what, under the circumstances, are extraordinary measures with no foreseeable benefit, should not be accepted by the courts or society at large. Although religion and culture assist in better understanding the context of decisionmaking, it should not impinge on the rights of others. To make religion a factor in allocating a hospital bed is inequitable, for it privileges religious patients over others who may need care more urgently and whose chance of a favourable outcome may be better.

Third, it is right that families who have strong beliefs, religious or otherwise, about the deaths of their loved ones be heard. In dying, just as in living, procedural fairness must be respected. The judge in Mr. Golubchuk's case noted that "communication broke down between the [family] and the physicians" and criticized the hospital for not following the recommendation of the Canadian Critical Care Society, which recommends "recourse to either mediation or adjudication" in cases of impasse. ${ }^{2}$ By not providing impartial, arm's-length mediation as part of a well-established process including clear rules and laws, the hospital paid dearly: it was sued.

Finally, it may be worthwhile to consider law reform. The State of Texas, for example, enacted the Texas Advance Directive Act, 1999, which provides a framework and a timeline for resolving disputes. ${ }^{5}$ It outlines the process for families and physicians to talk and includes a disputeresolution mechanism as well as a time limit of $\mathrm{I} 2$ days. If the process fails, the hospital, in conjunction with the family, must try to arrange transfer of the patient to another physician or institution willing to give the treatment requested by the family. If no such provider can be found, the hospital and physician may unilaterally withhold or withdraw therapy that has been deemed futile, although the patient or surrogate can ask a state judge for an extension of time. In a recent study of the implementation of this directive over 2 years at Baylor University Medical Center in Dallas, Texas, the authors found that the data "suggest that the law represents a first step toward practical resolution of this controversial area of modern health care." Although the whole law is not perfect, it offers an instructive example. And first steps are important. 


\section{EDITORIAL}

FRANÇAIS À LA PAGE SUIVANTE

Ultimately, neither side in the Golubchuk case seems especially in the right. The hospital failed the family by not giving them a fair and impartial hearing, and the family failed society by using their religion to privilege their father over other needy patients. As the judge noted, the 2 sides "might have avoided litigation" if they had used "a knowledgeable, trained and objective mediator." ${ }^{2}$ To avoid future failures, widespread adoption of formal mediation processes, or even better, laws like that in Texas, would provide much needed clarity.

\section{Amir Attaran LLB DPhil}

Canada Research Chair in Law, Population Health and Global Development Policy

University of Ottawa

Ottawa, Ont.

Paul C. Hébert MD MHSc

Editor-in-chief

CMAJ

\section{Matthew B. Stanbrook MD PhD}

Deputy Editor, Scientific

CMAJ

With the Editorial-Writing Team (Rajendra Kale MD, Barbara Sibbald BJ, Ken Flegel MDCM MSc and Noni MacDonald MD MSc)

Competing interests: See www.cmaj.ca/misc/edboard.shtml

\section{REFERENCES}

I. CTV.ca news staff. Orthodox Jew to remain on life support, trial next. CTV [Winnipeg] 2008 Feb I3. Available: www.ctv.ca/servlet/ArticleNews/story/CTVNews /20080213/life_support_080213/20080213?hub=Health (accessed 2008 Mar 25)

2. Golubchukv. Salvation Army Grace General Hospital and others, 2008 MBQB 49. Available: www.canlii.org/en/mb/mbqb/doc/2008/2008mbqb49/2008mbqb49 .html (accessed 2008 Mar I8)

3. Dehn K. Kelly Dehn covers the family's battle [video]. CTV [Winnipeg]. 2008 Feb I3 Available: www.ctv.ca/servlet/ArticleNews/story/CTVNews/200802I3/life_support 080213/20080213?hub=Health (accessed 2008 Mar I8)

4. Airedale NHS Trust v. Bland [1993] I All ER 82I (Eng. Family Div., Eng. C.A. and H.L reported together).

5. Fine RL, Mayo TW. Resolution of futility by due process: early experience with the Texas Advance Directives Act. Ann Intern Med 2003;139:743-6 